\title{
The Strategic Partnership Cutting the Costs or not
}

\author{
Mohammad Saleh Miralam \\ University of Business and Technology, Jeddah, Saudi Arabia
}

\begin{abstract}
There are numerous articles which have been written about strategic partnership and how they can be beneficial for both buyer and supplier. The aim of this article is to find out the ways of how the strategic partnership cuts the costs by using semi-structured interviews. Semi-structured interviews were found to be the most appropriate method of data collection because they enabled the researcher to gather valid and reliable data. Ten companies have been interviewed in different industries in Saudi Arabia (four in computer industries, three in bank industries, and three in food industries). The article gives a valuable resource and rich information for those interested to know more about the Saudi market or those wishing to invest in it. All interviews were conducted with purchasing managers by using semi-structured interviews. The study found that the strategic partnership does cut the costs. Cutting the costs comes from sharing skills and information, reducing the investment risk, and decreasing the operation costs.
\end{abstract}

Keywords: strategic partnership, outsourcing, buyer-supplier relationship, subcontracting

\section{Introduction}

Today, most companies are looking for outsourcing to enhance their competitiveness in the market. Outsourcing constitutes an alliance between two parties who work together to achieve their goals and interests. When firms contract, subcontract, or externalize non-core activities to free up cash, personnel, time, and facilities for activities, where the firm holds competitive advantage, this is called outsourcing. Firms concentrate on what they do best and they contract out to others. Thus, by outsourcing firms provide more flexible, faster, cheaper, and effective services. Outsourcing is often an integral part of downsizing or reengineering.

The researcher found that behavior in the relationship between buyer and supplier is the important factor for outsourcing to be successful. This article aims to find out "the strategic partnership cuts the costs or not", and how. This article let people to understand the strategic partnership in close and clarify one of the important advantages from using it, which is reducing the cost. For collecting the data, the researcher set the following question to be asked for the interviewers:

(1) Is the strategic partnership important to your organization? And how?

(2) From cost perspective, how strategic partnership can be beneficial to your organization?

This article represents an important contribution to the business field in Saudi Arabia which has never been studied from such a perspective, so the research provides a valuable resource for those interested to know

Mohammad Saleh Miralam, Ph.D., assistant professor and faculty member at College of Business Administration, University of Business and Technology, Jeddah, Saudi Arabia.

Correspondence concerning this article should be addressed to Mohammad Saleh Miralam, University of Business and Technology, P. O. Box: 127377, 21352, Jeddah, Saudi Arabia. E-mail: m_miralam@yahoo.com. 
more about the Saudi market or those wishing to invest in it. In addition, unlike other articles, this one has been conducted in different manufacturing and service organizations in the Saudi market (computer industries, bank industries, and food industries) thereby providing rich and varied information from different perspectives, which can be generalized to represent the business climate in the Saudi market as a whole. In addition, this article concentrates on strategic partnership and represents one of the most important advantages from applying. Finally, this study also provides useful information for researchers interested in the same subject area, because it is a rich source of strategic relationship information which could be applied in other countries around the world. In other words, the study could be generalized to other countries.

To achieve the research objectives, the researcher decided to choose and use semi-structured interviews, to give the researcher the ability to change interview direction, and to open up new aspects of the subject during discussions.

The data were analyzed personally using a number of steps. The first step was to transcribe the data collected and the second step was to translate this data from Arabic into English as the interviews had been conducted in Arabic. Subsequently, the researcher classified all the data into categories and units.

\section{Literature Review}

During the past few years, many studies about buyer-supplier relationships have been conducted (Sharma, 1997; Eizenhardt, 1989), and most of them have been exhorting managers to move towards longer-term and collaborative strategic partnerships with external business partners instead of arm's-length relationships. Dubie (2003, p. 4) mentioned in her article that Glore, who is the chief of implementation and standards for the Department of the Air Force at Patrick Air Force Base in Florida, stated that "Outsourcing gives us the higher caliber technical people we need and a better sense of continuity in the long term".

Outsourcing is defined as a delegation of some firms'/companies' in-house operations/processes to a third party to accomplish the firms'/companies' needs. Today, for services and products, outsourcing has become commonplace. Most companies are looking for outsourcing to enhance their competitiveness in the market. Outsourcing constitutes an alliance between two parties who work together to achieve their goals and interests. Both parties need to make special efforts for outsourcing to be successful. Hence, it is important for buyers and suppliers to understand each other clearly and in depth to avoid any problems to achieve successful outsourcing. By outsourcing non-strategic activities, an organization can reduce its size and make it less hierarchical, allowing it to focus on obtaining, developing, and motivating the people who create value, and helping to allow management to shift their attention toward strategic activities, coordination, and the skills that promote competitive success (Klepper \& Wendell, 1998).

There are many types of relationships between buyers and suppliers (market exchange, captive buyer, strategic partnership, and captive supplier) (Bensaou, 1999), one of which is seen as a strategic partnership. Since the 1960s, Japanese producers have achieved notable growth by using strategic subcontracting. Subcontracting consists of a series of collaborative relationships based on problem-solving principles for the manufacture of high-quality, low-cost goods, and on time delivery (Nishiguchi \& Brookfield, 1997).

In this relationship, partners work together from the beginning of concept design to the development of tooling and manufacturing processes to the coordination of just-in-time production and delivery between the two firms. The relationship between buyer and supplier is usually a close, long-term relationship, because it involves a number of investments between them. 
In such a relationship, there is a high level of interaction and interdependency between buyer and supplier. Information is regularly exchanged between partners by reports or face-to-face meetings to exchange and discuss ideas about future plans and improvements and controlling tasks. The social climate in strategic partnerships is trusting and collaborative, and there is a strong commitment between buyer and supplier to continue the relationship.

\section{Methodology}

Interviews are classified into three types: structured, semi-structured, and unstructured (Saunders, Lewis, \& Thornhill, 2003). A structured interview (also known as a standardized interview) can be used within a quantitative or qualitative questionnaire. The aim of using the structured interview is to ensure that each interviewee is presented with exactly the same questions and this ensures that answers can be reliably aggregated. The researcher should read out questions exactly as they appear in the survey and in the same tone of voice, to give all interviewees the same opportunity and freedom to answer each question (Kvale, 1996).

A semi-structured interview is considered as a two-way communication and can be used both to give and to receive information. Unlike the structured interview, where details of questions are prepared ahead of time, semi-structured interviewing starts with more general questions or topics. Not all questions are designed and phrased ahead of time. The majority of questions are created during the interview, allowing both the interviewer and the person being interviewed the flexibility to probe for details or discuss issues. Although the researcher has a list of themes and questions to be covered, interviews may be varied from interview to interview, which means that the order of questions is not fixed and the researcher may omit some questions in particular interviews, depending on the flow of the conversation. The responses received from such interviews are usually recorded by note-taking or tape-recording (Saunders et al., 2003).

Unstructured interviews are used when researchers wish to explore a general subject in depth. There is no specific set of questions asked in a predetermined order although the researcher needs to have a clear idea about the subject. An unstructured interview can go in any direction depending on the conversation flow, so it gives interviewees the opportunity to talk freely about their opinions and beliefs in relation to the subject, with guidance from the interviewer (Easterby-Smith, Thrope, \& Lowe, 2002).

The researcher therefore decided to use semi-structured interviews to collect the research data. A semi-structured interview was deemed as the most appropriate type of interview because it is flexible enough to give the researcher the ability to change interview direction and to open up new aspects of the subject during the discussion. Questions (see introduction) had been set in advance to guide the interview. Interviews (semi-structured interviews) found the best method of data collection to gather valid and reliable data. A semi-structured interview is considered as a two-way communication and can be used both to give and receive information.

The researcher found that the most appropriate interviewees for such study were people responsible for purchasing because they had full information about suppliers, their history and behavior of the relationship.

These sectors (computer industries, bank industries, and food industries) have been chosen because they found that they are the most rapid growing and developing ones in Saudi Arabia market after petroleum and petrochemical, and they have a significant effect on Saudi economy as described below.

There are 550 food factories in Saudi Arabia and they employ 46,000 workers. Because of the successful policies of the Saudi Arabian food industry, such as encouraging factories to export their production and give full attention to their quality monitoring, Saudi Arabia has become an attractive market for foreign companies 
and local investors. Studies show that improvements made in the packing industry in Saudi Arabia have played an important role in the success of the food industry. Production in food factories has increased by $53 \%$ within the last five years. Additionally, studies represent that there is a $4.5 \%$ annual fixed incremental rate of exports from the food industry in Saudi Arabia (Argaam, 2007).

Heavy government investment in developing Saudi Arabia's technology and internet infrastructure towards the end of the review period combined with efforts to maintain a highly competitive and open market in retail sales of computers and peripherals to whet the consumer appetite for higher spending on computers and peripherals during 2013. Tablets and other portable computers increased in retail volume by $48 \%$ in 2103 , while $6 \%$ retail volume growth was in laptops (Euromonitor, 2014).

Saudi Arabia is one of the world's fastest growing banking markets. Commercial banks that are operating in the competitive environment are likely to be more efficient in near future in the region amid technological developments and government favorable policies. Even in the wake of global financial turmoil, Saudi Arabian banking industry registered impressive positive growth results year to year. Saudi Arabia has a modern banking industry with 13 commercial banks. Saudi banks provide retail and corporate banking, investment services, brokerage facilities, and derivative transactions in addition to credit cards, Automatic Teller Machines (ATMs), and point-of-sale transactions. Saudi Arabia also has a thriving stock market. The total value of shares traded annually is some SR 60 billion (US \$16 billion) (Royal Saudi Embassy, 2014).

After the researcher had collected the data, he started to analyze the data personally. The first step was to transcribe all the data. The second step was to translate the transcribed data from Arabic into English because Arabic was the main language of all the interviews. After all the data had been translated into English, the researcher classified all the data into categories. The researcher found that there was valuable data to assist in the understanding how strategic partnership can cut the cost.

The researcher regarded ethical issues as an important success factor for the research process. First of all, privacy was given full consideration during the research process. The interviewees' names were kept anonymous, as most of them had requested. Secondly, anything that interviewees said or gave (documents) during the interviews was not used out of the research. All data was used only for the research purpose. Finally, all interviewees knew about the tape-recorder before the interviews began.

\section{Findings and Discussions}

\section{Sharing Skills and Information}

Seven of interviewed companies (three in computer industry, two in bank industry, and two in food industry) mentioned that a strategic partnership assists partners to get access to global market and resources and helps partners to build trust and good communication, which makes the information and skills that they use equilibrium between them. This means that partners can gain and exchange new research, product design, any development and implementation from each other, which leads to cutting costs. As three mangers (two in computer industry and one in bank industry) said, "in strategic partnership, no secret, if we want the partnership to work". Other two managers (one in computer industry and one in food industry) explained that the relationship between partners in strategic partnership should be comfortable and transparent, for example, suppliers of three companies (two in computer industry and one in bank industry) discovered new techniques to develop their work practices for improving product cheaply. These suppliers shared all new techniques information and skills with their buyers. 


\section{Reducing the Investment Cost}

Seven companies work on minimizing the investment costs to cut the costs (three in computer industry, two in bank industry, and two in food industry). Investment costs are very high for development. That is why many companies are encouraged to share investment costs through strategic partnership. In strategic partnership, partners may invest in each other or they may invest both in one project. Six managers (three in the computer industry, one in the bank industry, and two in the food industry) mentioned that instead of each party spending a lot of money and time in developing or enhancing products or services on their own, both parties can invest and work together to achieve the same result, for example, one manager in the bank industry said, "Our company does not invest money for development alone; all our projects are shared with partners (suppliers)". Two other managers in the food industry said, "By using strategic partnership, we get a chance to grow the existing business and create new ones without spending a lot of money".

\section{Decreasing the Operation Costs}

Most of interviewed companies (nine companies) explain that strategic partnership is alliance. The alliance means agreement among parties or a formal declaration to work jointly. This type of contract sets the rules, responsibilities, processes, and expectation for each party. Therefore, working jointly implies that parties should not duplicate the work. There are many of works and mission that can be done by one of them for both, which leads to reduce costs, for instance, three mangers (one in bank industry and two in computer industry) said, "This type of relationship lets us work in sustainable and competitive manner in the market by reducing the operation cost".

The alliance can lead to establishing an appropriate structure among partners to avoid employees or mangers who are doing the same works, which is, as a result, a reduction in operation cost achieved as six managers mentioned (two in bank industry, two in computer industry, and two in food industry), for instance, two managers said, "Many positions in organization structure can be joint together for both sides in strategic partnership. Buyer and supplier can assign the required employees to work for both parties, such as monitoring employees as a collaboration between them".

\section{Conclusions}

Finally, the main objective of this article was to study in-depth strategic partnership and shows how strategic partnership can reduce the cost in the Saudi Arabian market. The article's significance derives from the following main factors. First factor is that this article represents an important contribution to the business field in Saudi Arabia which has never been studied from such a perspective. Second factor is that this one is conducted in different manufacturing and service organizations in the Saudi market (computer industries, bank industries, and food industries) thereby providing rich and varied information from different perspectives, which could be generalized to other countries. Finally, this article concentrates on strategic partnership and represents one of the most important advantages from using it.

The study found that strategic partnership is one of the important relationships between buyer and supplier. By using such relationship, many advantages can be achieved (see literature). One of the advantages is reducing the cost, which can occur, as the researcher found, by sharing skills and information, reducing the investment cost, and decreasing the operation costs. Sharing skills and information assists partners to get access to global market and resources. This allows partners to gain and exchange new research, product design, any 
development and implementation from each other. Reducing the investment cost can be achieved by sharing investment between partners. Decreasing the operation costs can occur by avoiding the duplicate work and establishing an appropriate organization structure.

\section{References}

Argaam. (2007). Food industry in Saudi Arabia. Retrieved from http://www.argaam.com/frontend/CompanyNewsDetail.aspx? id $=43567$

Bensaou, M. (1999). Portfolios of buyer-supplier relationships. Sloan Management Review, 40(4), 35-35.

Dubie, D. (2003). Outsourcing management gets a second look. Retrieved from http://www.nwfusion.com/news/2003

Easterby-Smith, M., Thrope, R., \& Lowe, A. (2002). Management research (2nd ed.). London: SAGE Publication, Inc..

Eizenhardt, K. (1989). Agency theory: An assessment and review. Academy of Management Review, 14(1), 57-74.

Euromonitor International. (2014). Computers and peripherals in Saudi Arabia. Retrieved from http://www.euromonitor.com/ computers-and-peripherals-in-saudi-arabia/report

Klepper, R., \& Wendell, J. (1998). Trends favoring outsourcing. Retrieved from http://ist-socrates.berkeley.edu/ fmb/articles/ outsourcingtrends.htm

Kvale, S. (1996). Interviews: An introduction to qualitative research interview. London: SAGE Publication, Inc..

Nishiguchi, T., \& Brookfield, J. (1997). The evolution of Japanese subcontracting. Sloan Management Review, 39(1), 89-89.

Royal Saudi Embassy. (2014). Banking in Saudi Arabia. Retrieved from http://www.saudiembassy.net/about/country-information/ economy_global_trade/banking.aspx

Saunders, M., Lewis, P., \& Thornhill, A. (2003) Research methods for business students (3rd ed.). Upper Saddle River: FT Prentice Hall.

Sharma, A. (1997). Professionals agent: Knowledge asymmetry in agency exchange. Academy of Management Review, 22(3), $758-758$. 